\title{
SOME OBSERVATIONS ON THE VISUAL FIELDS IN HYDROCEPHALUS
}

\author{
BY
}

\author{
E. B. C. HUGHES
}

(Received 8TH November, 1945)

THE value of quantitative perimetry in the diagnosis of intracranial diseases, and of intracranial tumour in particular, has long been recognized. The field defects resultant from lesions of various portions of the visual pathway have been studied in detail, and a voluminous literature has accrued on this theme. The field changes found in association with chiasmal lesions, secondary to pituitary tumours, and other parasellar masses, have been discussed perhaps more than any other aspect of this subject, not excepting the calcarine cortex, and yet scant attention has been given to chiasmal involvement from pressure by a distended third ventricle in obstructive hydrocephalus. Cheseldon in 1713, described a case in which severe flattening of the optic nerves and chiasma was present in association with hydrocephalus, and he is perhaps the earliest writer on this subject. Oppenheim (1911) states that " in hydrocephalus the middle part of the chiasma may be directly affected by the bulging of the floor of the third ventricle, and bitemporal hemianopsia may result." Wildbrand and Saengar (1913, p. 240) discuss in detail the pathological aspects of these cases, but only reproduce one visual field which shows bitemporal hemianopic central scotomata resulting from hydrocephalus. More recently, temporal defects have been recorded by Sinclair and Dott (1931), and homonymous, temporal and binasal defects have been published by Wagener and Cusick (1937) and by Weinberger and Webster (1941). The presence of binasal defects due to displacement of the optic nerves or chiasma by the distended third ventricle against the carotid arteries has been discussed by Cushing and Walker (1912). Most of their cases, however, showed advanced secondary atrophy.

In the course of careful quantitative perimetry in a large series of intracranial tumours, bitemporal visual field defects of varying form have been found frequently in association with hydrocephalus. A critical survey of these defects in different patients and a careful study of the behaviour of the defects in individual patients during the progress and regress of the syndrome have led to the belief that this field defect is of fairly constant form, undergoes a peculiar evolution, and is quite comparable to that seen in the upper temporal field in association with the pituitary tumours (Josefson, 1916). And, as in the latter case, it can be shown that apparently differing field defects are in reality but stages in a progressive process, and do not alter markedly from patient to patient. Some confusion of thought has been inevitable in writings on this subject, for patients with obstructive hydrocephalus so frequently have papillœdema at the time they seek treatment. The changes found with papillœdema are present at an early stage, and consist of enlargement of the blind spot and of the pericæcal amblyopic zone which tends to stretch out like a pointing finger towards the macular area, but seldom reaches it. The appearance of secondary atrophy, unforo tunately so often seen, adds field defects of its ow to confuse the issue (Fig. 1). The onset of secondar南 atrophy is heralded by loss of the peripheral field usually on the nasal side, and this is a simple and total loss of the peripheral field and not characterize by depression features. Although the field defects of secondary atrophy are quite characteristic, an clearly distinguishable from those to be described; in order to minimize confusion any case showing established secondary atrophy or who developed it within a short time of perimetry has been discarded from this series.

\section{Observations}

The field defects to be described all occurred in association with hydrocephalus and distension of the third ventricle, demonstrated either by ventriculography, by direct vision during the performance of a third ventriculostomy, or by post-mortem study. As stated above, those cases in which secondary optic atrophy was present or suspected have not been included, and in no case was there any reason to suspect causes other than distension of the third ventricle for the field defects.

The earliest change noted in the visual fields was the appearance of a very small paracentral scotoma in the apex of the lower temporal quadrant. This usually appeared at about the same time in both fields, but considerable variation between the two eyes was noted on occasion. At first the scotoma would be "thin," perhaps only demonstrable by a small visual angle such as $1 / 2000$, and at this stage the central isopters as a whole would not be affected in the lower temporal quadrant, but would merely step aside to skirt the scotoma should it cross their 

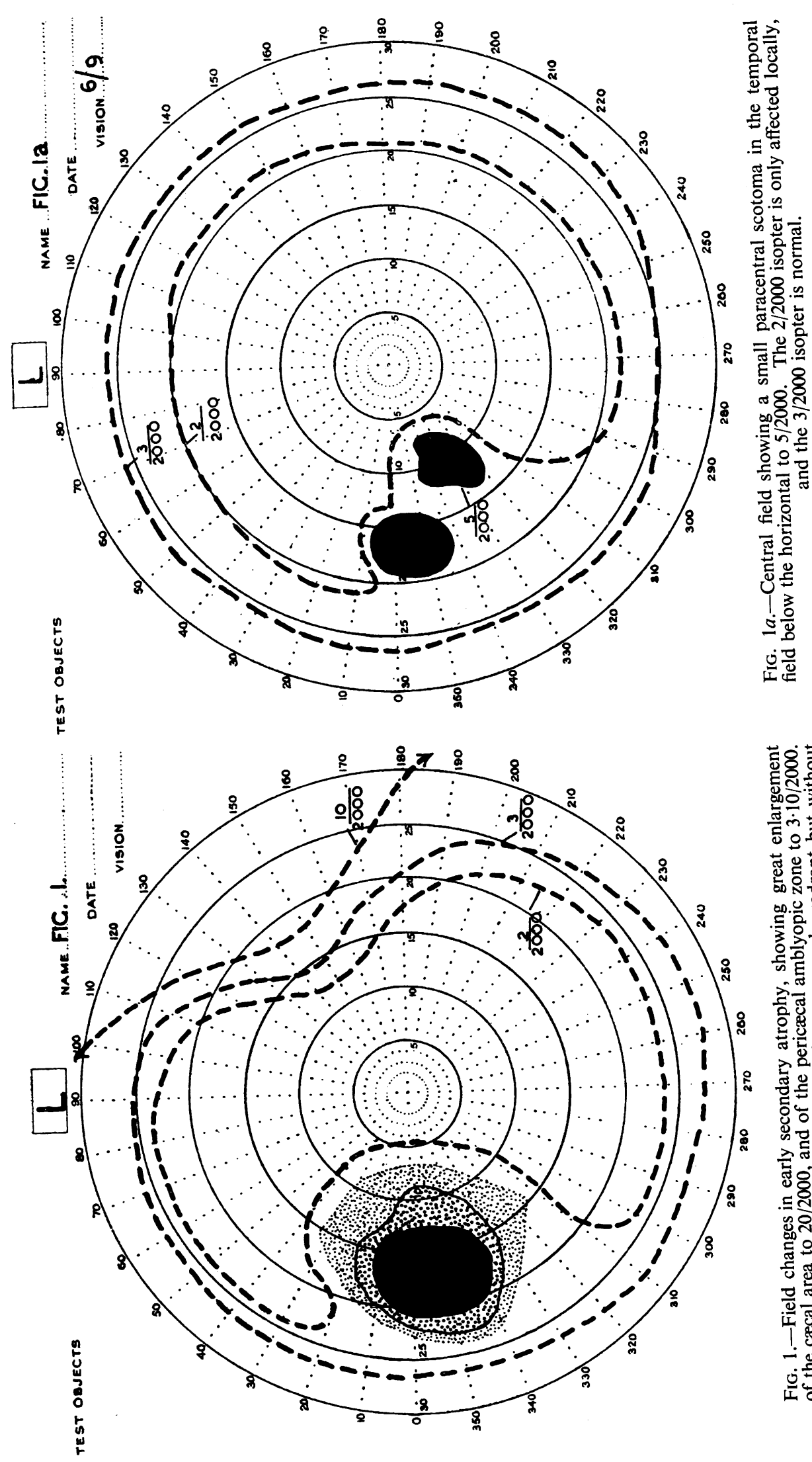

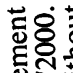

으응

要的节

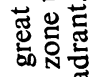

ㅇ․음 $\frac{\pi}{\sigma}$

要要

政

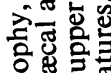

它.

겷.

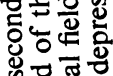

旅哥

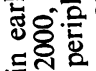

औั.

Еㄴ응

赵

可

10.

比焉

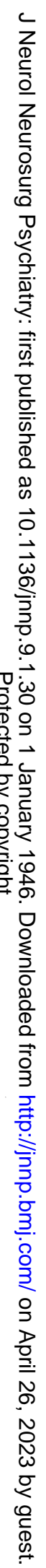


path (Fig. 1a). This scotoma often lay in the centro-cæcal area, usually nearer the blind spot than to fixation, and nearer the horizontal meridian than the vertical, although it has been found in many different positions. The presence of this defect seems to be a relatively early sign in dilatation of the third ventricle, and may precede other field changes by quite a long time. This field loss has not been encountered with suprasellar tumours, but this may well be due to the fact that in such cases the visual field loss has usually been well advanced by the time that treatment was sought. The scotoma then usually enlarged gradually to a small visual angle, although it has been observed that the central nucleus to a large visual angle might remain quite small in some cases. As it enlarged the adjacent isopters became involved locally, but at points distant from the scotoma they remained in their normal position (Fig. 2).

The next change that took place was a curious one, and one that is found in association with lesions of many parts of the visual pathway. Although it commonly followed on the scotoma development, it might rarely precede the scotoma, or, more rarely still, might be the only field change found, a scotoma never appearing. This change consisted of a depression in acuity in the affected quadrant and could be demonstrated by two characteristic peri- $c$ metric features. The first feature is the better known $z$ of the two, and comprises a recession of the internal isopters. That is to say the position of, for example, the $1 / 2000$ isopter will be most affected in the lower temporal quadrant, and the isopters of progressively larger visual angles will be less and less affected so that the peripheral isopter for, say, 1/330 may be quite normal (Fig. 3). The second feature is less well known and appreciated, and has never been clearly described, although many authors have hinted at its presence. If a white test object be placed in the normal lower nasal field, the subject will see it as a clear white round object. If the same object be placed in the affected quadrant, the lower temporal, it no longer appears as a bright white object, but will be variously described as " dull," " smudged," " greyish," " pale green," " hazy," or " not quite round." "Dirty grey" is the term most often used by patients to describe it, and this feature has in consequence been termed "greying " of the field by the author in an earlier report (Hughes, $\vec{\overrightarrow{ }}$ 1943). This greying of the visual field is an odd and surprising feature, and is perhaps seen more commonly in chiasmal lesions than with lesions elsewhere in the visual pathway. In the cases here 6 discussed, it has tended to affect the whole of the

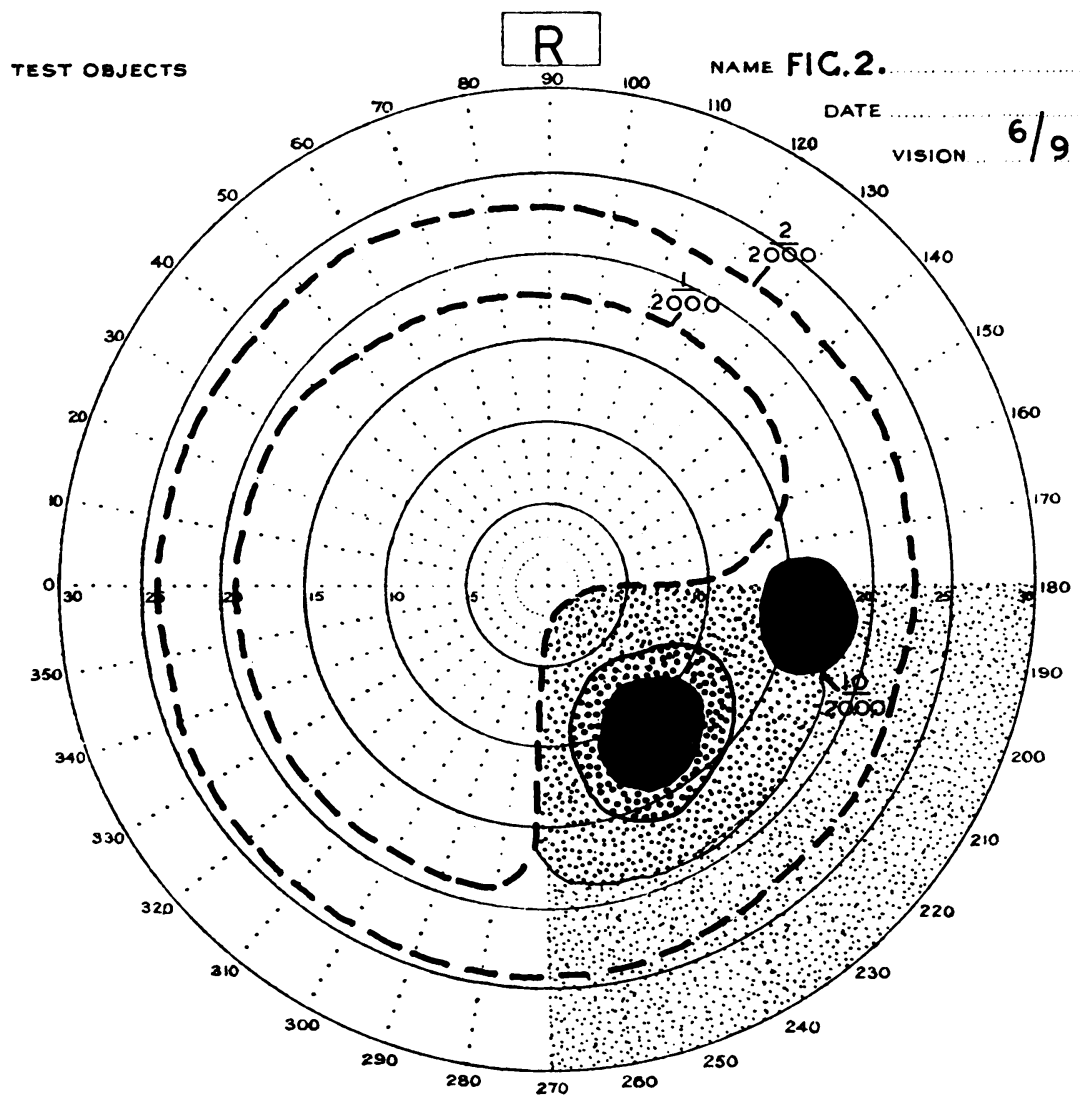

Fig. 2.-Central field showing a more advanced scotoma in the lower temporal quadrant. There is a relative scotoma to $10 / 2000$, and absolute nuclei to $2 \cdot 10 / 2000$. The isopter for $2 / 2000$ is unaffected. 


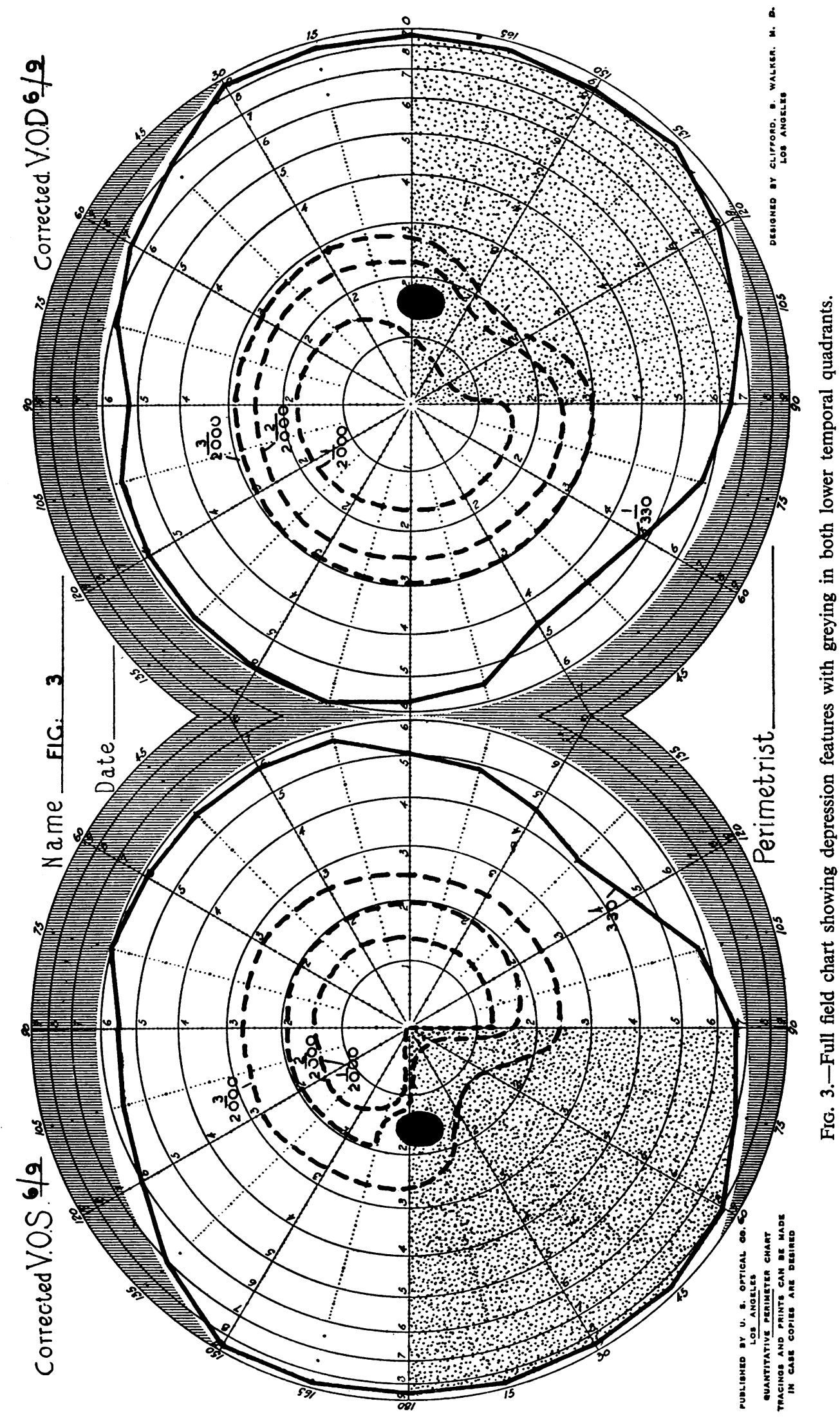


lower temporal quadrant, and that uniformly. That it should stop abruptly at the vertical meridian is hardly surprising since it is the crossed fibres that are affected, but in many cases it terminates quite as sharply at the horizontal meridian. Astonishing though this might appear, it is, nevertheless, a perimetric feature which runs true to form, for when a whole quadrant is lost in a chiasmal lesion the line of field loss most frequently runs exactly along the horizontal meridian as well as the vertical. It is most important to realize that this greying of the field is not entirely dependent upon depression of the field, for although greying is nearly always present in a depression field defect, it may occur when even the isopters of $1 / 2000$ are quite normal (Fig. 4).

It seems necessary at this stage to make a clearcut distinction between the two types of field defect. In the scotomatous variety, there is a localized amblyopic zone in an area of the field, which may be relative or absolute, and will affect isopters of all visual angles normally visible in this area. The isopters are affected not in virtue of the visual angle concerned, but by the presence of a scotoma in an area of the field through which they run. In a depression type of field, all isopters over a wide area of the field are affected at the same time, those of the small visual angle being naturally affected first and most severely. In its early stages there is no actual loss in the visual field, and a large test object may be seen, although dimly, over the whole normal extent of the field. When absolute field loss occurs, it takes place at the periphery of the field by an indrawing of the most peripheral isopter, so that an area of field loss appears in which no stimulus, however great, can be seen. This area may be very small at a time when there is complete quadrant loss to smaller visual angles. Paradoxically, then, this type of field loss affects the central isopters first, but total field loss first appears at the periphery.

The further progress of the field defect in the cases reported here depended on the relative pro- $\bar{C}$ portion of scotomatous or depression features present. In the pure depression type of field, the internal isopters failed first, in the lower temporal $\stackrel{\mathbb{Q}}{\Omega}$ quadrant, and were followed in regular order by the o isopters of larger and larger visual angles until the most peripheral isopters were indrawn, and a state of affairs was reached in which there was actua peripheral loss of the field. This process continued until most of the lower temporal quadrant had been lost (Fig. 5). It was usually found that the extreme apex of the quadrant was spared to the extent of $2^{\circ}-3^{\circ}$. At this stage, depression features were some times noted in the upper temporal quadrant, namelof

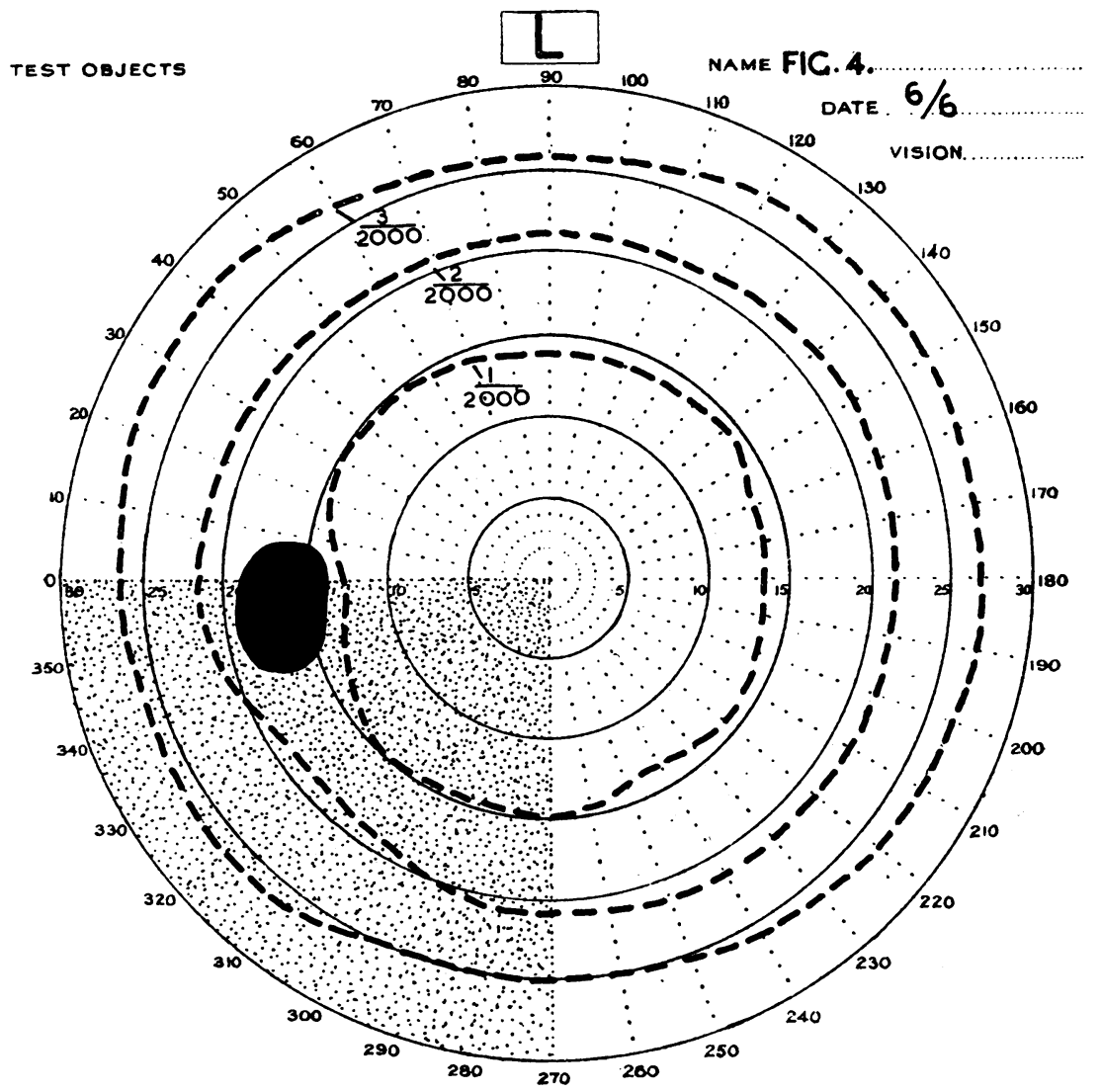

FIG. 4.-Central field showing greying of the lower temporal quadrant in the presence of normal isopters for $1 \cdot 2 \cdot 3 / 2000$. 


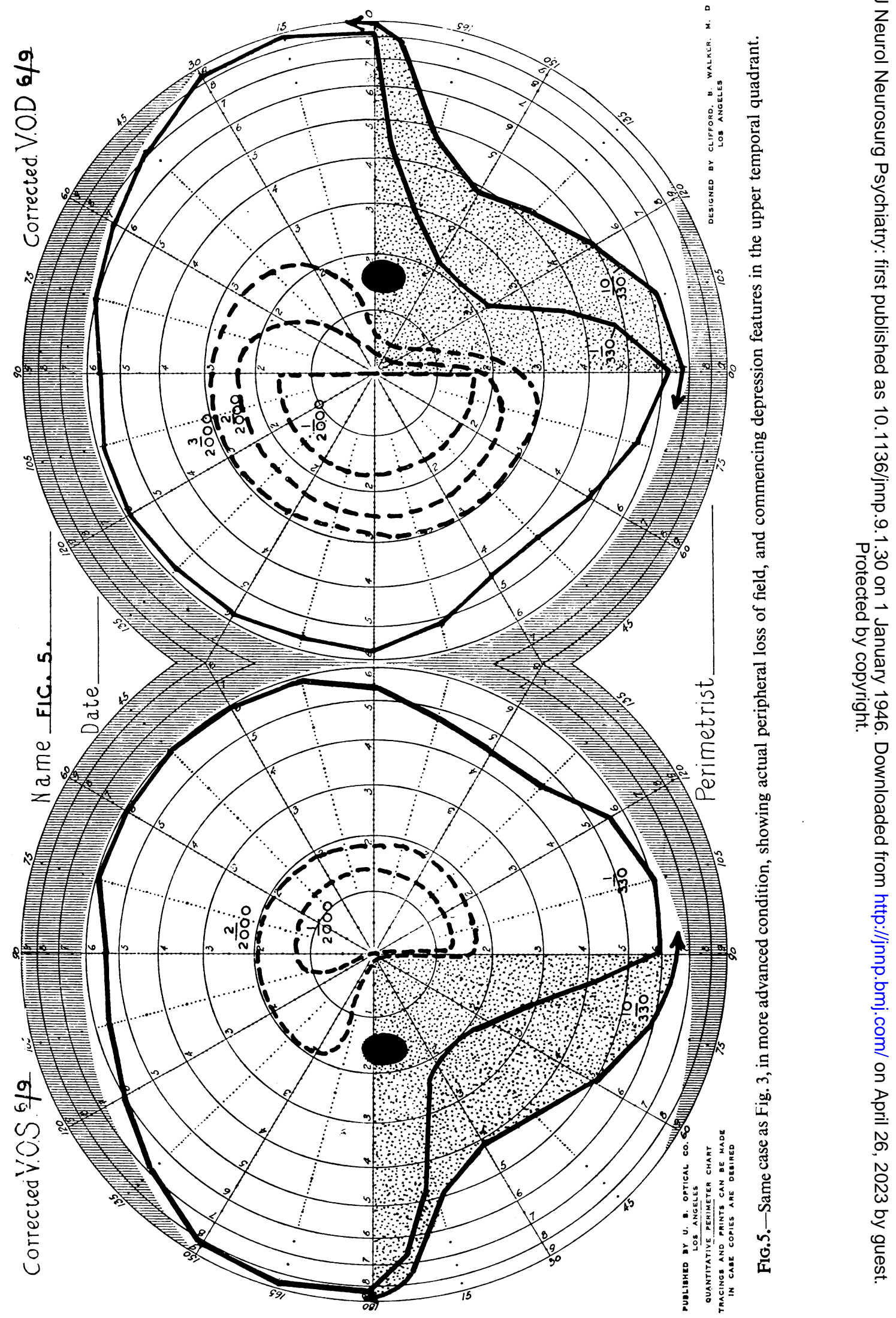


E. B. C. HUGHES
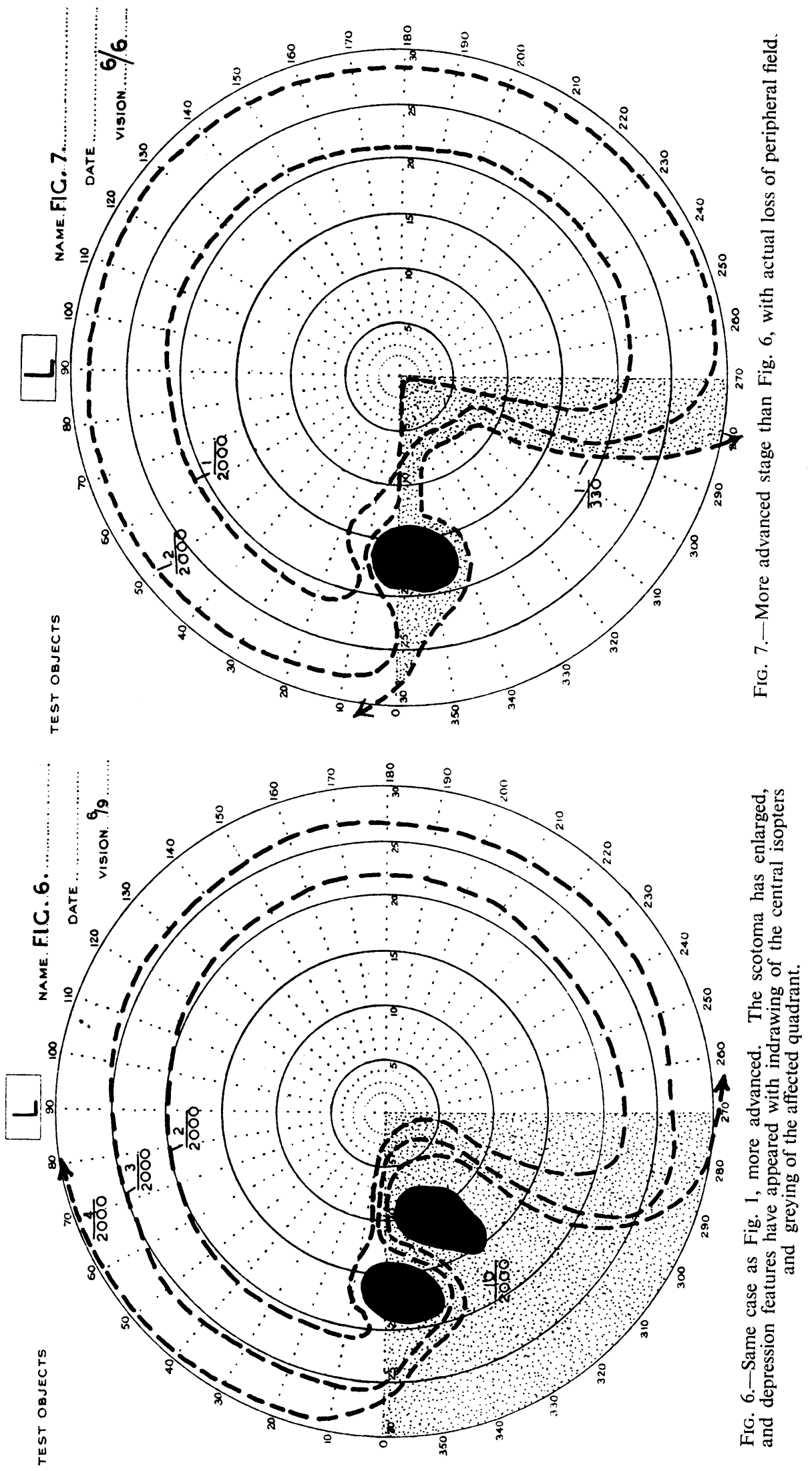

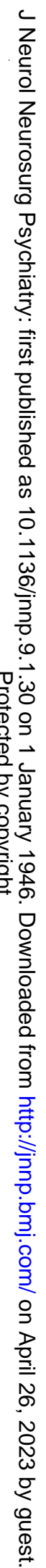


an indrawing of the internal isopters, and a quadrantic greying. It was not common, however, to find this even when the lower quadrant was severely affected. Presumably, were this defect to progress, it would follow the same trend as the field in cases of pituitary tumours and result in progressive loss of the upper temporal quadrant and then invasion of the nasal field. No case, however, was encountered in this series in which the whole of the temporal field had been lost. Complete bitemporal hemianopia, in fact, seems rarely to have been observed, and many of the authors quoted have stressed this point. The question of loss in the nasal field is taken up below.

Where scotoma formation was the predominant feature, the course of events was somewhat modified. The original scotoma enlarged and came to occupy most of the lower temporal quadrant. At the same time, depression features usually appeared with indrawing of the internal isopters and greying (Fig. 6). Then the peripheral isopters became involved, either by the progress of the depression feature, or by actual enlargement of the scotoma, and an incomplete quadrant loss would be found (Fig. 7). It was not uncommon at this stage for a small scotoma to appear in the upper temporal quadrant in a position comparable to its first appearance in the lower quadrant (Fig. 8). Presumably, were the process to continue, the upper and lower scotomata might coalesce, producing an hemianopic central scotoma similar to that seen so often with pituitary tumours. Such does not seem to be the case with this type of field defect; the next stage consisted of an invasion of the fixation area at the apex of the lower temporal quadrant by the scotoma, followed by an invasion of the fixation area in the upper quadrant and finally on the nasal side of the fixation (Fig. 9).

It is clear that many different combinations of depression and scotoma might be expected to occur, but an attempt has been made here to sort out general principles underlying the process, and to stress the fact that individual variations encountered are usually stages in a progressive process rather than characteristic of the individual. The incidence of these field defects in all cases with hydrocephalus has been impossible to determine. Many have been first seen in an unco-operative state when perimetry has been impossible. In many others who might have shown such field defects at an earlier stage the perimetric picture has been so overshadowed by severe secondary atrophy that proper assessment has been impossible. Of the remaining cases in which adequate perimetry has been possible somewhat over half have shown these defects in one or other form.

\section{Discussion}

The etiology of this field defect has not seemed in doubt. All cases were hydrocephalic from obstruction at the level of the Sylvian aqueduct or below, and there was no suggestion in any case that there might have been direct involvement of any part of the visual pathway by tumour. Some of these defects, in fact, occurred in association with simple obstructions in the roof of the fourth ventricle, or in benign stenosis of the aqueduct.

That the distended anterior end of the third ventricle can press forwards and downwards on to the chiasma, and even displace the chiasma forwards, there has been abundant proof from operative and post-mortem studies, and excellent histological sections showing this have been published by Wildbrand and Saenger (1913, Plate XII and XIII, Fig. 80,81 on p. 238). In several cases an opportunity to study the relations of the chiasma and third ventricle during life was afforded during the performance of an anterior third ventriculostomy operation. In these cases, the chiasma was often seen to be displaced forwards so greatly, that even the anterior margin of the chiasma was convex forward. The relationship of the third ventricle to the chiasma has been studied in great detail by de Schweinitz (1923) and Schaeffer (1924) and there can be no doubt that great individual variations may be found in the site of the chiasma. One might imagine, therefore, that pre- or post-fixation of the chiasma would have a considerable influence on the portion of the chiasma affected and the consequent field changes. It is well known that prefixation of the chiasma will allow a pituitary tumour to pass backwards and upwards behind the chiasma, and so give rise to central scotomatous field changes often in the lower temporal quadrant rather than the upper temporal defects more often seen. Such wide variation is not so possible in the case of pressure from a distended third ventricle, for, whatever the site of the chiasma, the normal third ventricle is always wholly above and behind it. If the chiasma is post-fixed, or in its normal position, the third ventricle will tend to enlarge against its posterior aspect, and to spread over its superior surface. This type of pressure is usually associated with the depression type of visual field defect. If the chiasma is pre-fixed, then the ventricle will tend to exert most of its pressure effects against the posterior and inferior aspect of the chiasma, and the ventricle may even appear from beneath the chiasma between the two optic nerves in front. It is in such cases that the central scotomatous changes are found, and the field defect may be very similar to that found with a pituitary tumour extending upwards behind the chiasma.

Traquair (1942) has suggested that a scotomatous field change is suggestive of activity in a chiasmal lesion, and non-scotomatous of a slowly progressing or stationary lesion. The inferences drawn above suggest that the type of field defect is dependent on the site of the lesion rather than on the activity of the process. The basis for this observation does not depend only on the half-dozen odd cases in the above series in which the position of the ventricle relative to the chiasma was known for certainty, but on a much larger series of chiasmal field defects from all causes, mostly pituitary tumours. 

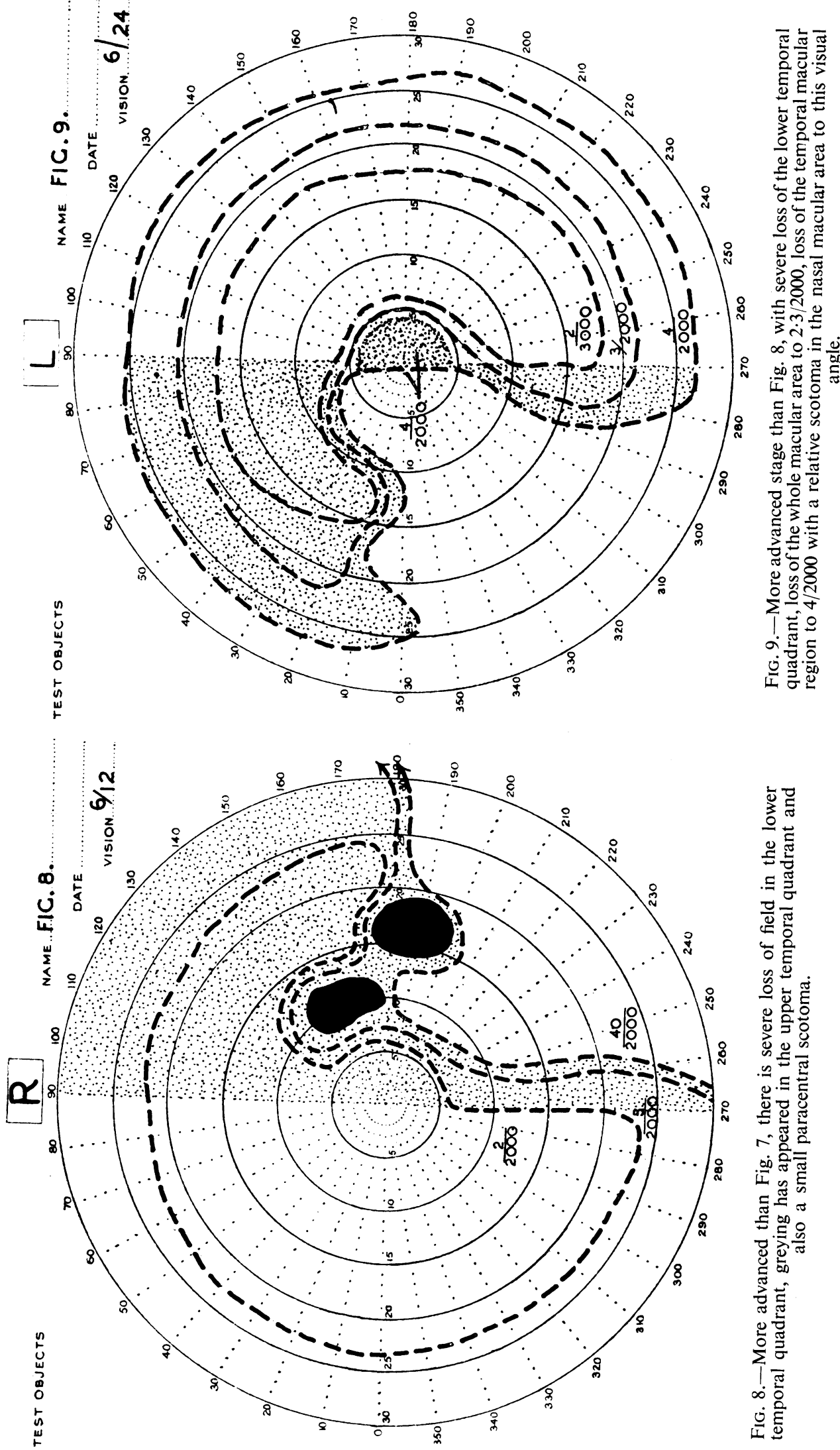

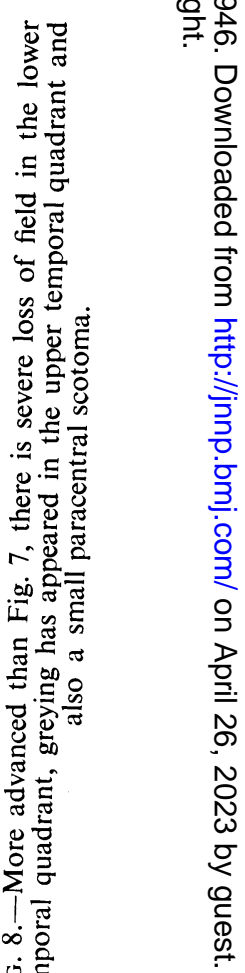


Great stress has been laid in the past on the relationship of normal and abnormal vessels to the chiasma, and it has been suggested that many field defects may be caused by displacement of the chiasma against adjacent vessels rather than by direct pressure from the displacing tumour. With the relatively soft pituitary adenoma post-mortem examination has shown such deep indentation of the optic nerves, chiasma or tracts by vessels that they must undoubtedly have caused field defects. In the cases under consideration, this hypothesis seems unlikely, for the distended ventricle spreads out over the chiasma and effectively protects it from the superjacent vessels, and would tend also to push it away from the subjacent posterior communicating artery. The only vessel which might conceivably play a part is the internal carotid, and displacement of the chiasma against this vessel would give a nasal type of field loss, totally different from the loss described above.

Some authors, and particularly Cushing and Walker (1912, loc. cit.), have stressed binasal field defects as characteristic of distension of the third ventricle. Although these authors were quite aware of the possibility of bitemporal field defects occurring, and quote Oppenheim (1911) on this subject, yet they state that bitemporal hemianopia " never seems to occur." This observation from two observers of such high repute cannot be neglected. The cases they described were a heterogeneous 'collection comprising hemisphere and posterior fossa tum zurs, and one case of fairly definite Leber's familial optic atrophy. The only feature common to them all was papillœdema and secondary optic atrophy. These authors suggested that in the "normal" consecutive optic atrophy one might expect to see an even and widespread loss of visual field, corresponding to contraction of scar tissue over the whole extent of the nerve, but that with distension of the third ventricle the chiasma is displaced outwards against the carotid vessels so that fibres from the nasal field are affected. The nasal field fibres affected by two pathological processes are, therefore, the first to show clinical evidence of damage. Paton (1909) in discussing the relationship between optic neuritis and cerebral tumour was not satisfied that secondary atrophy was invariably the cause of loss of vision in these cases, and suggested pressure by a distended third ventricle as an additional cause. He did not, however, make any observations on the type of field defect present. Secondary optic atrophy is, unfortunately, still not uncommon with cerebral tumour, but the field defects produced by this process are fairly characteristic and easily distinguishable from those of the simple hydrocephalus. In the author's experience, early loss of the peripheral nasal field is a constant feature of secondary atrophy, whatever the primary lesion may be, and is found equally often in those cases with a distended third ventricle as in those without.

\section{Summary}

1. A very brief review of the literature on field defects in association with hydrocephalus is given.

2. The progressive field changes found in this condition are described and divided into scotomatous and depression types of field defect. The essential difference between these two types is stressed.

3. The etiology of the field loss is discussed, and the effect of pre-fixation and post-fixation of the chiasma, of the relation of various vessels of the circle of Willis, and of secondary optic atrophy are discussed.

I am indebted to Mr. Harvey Jackson for permission to publish the records of many of these cases. I should like also to express my thanks to Professor Jefferson for the amount of care and time he has spent in helping me with the preparation of this paper.

\section{REFERENCES}

Cheselden, W. (1713). Phil. Trans., 28, 281.

Cushing, H., and Walker, C. B. (1912). Arch. Ophthal., 41, 559.

Hughes, E. B. C. (1943). Trans. Ophthal. Soc. U.K., $63,143$.

Josefson, A. (1916). Quoted by H. M. Traquair, Intro. to Clin. Perimetry, London, 1942, p. 204.

Oppenheim, H. (1911). Textbook of Nervous Diseases, Vol. 2, Edinburgh.

Paton, L. (1909). Brain, 32, 65.

Schaeffer, J. P. (1924). Anat. Rec. 28, 243.

de Schweinitz, G. E. (1923). Trans. Ophthal. Soc. U.K., 43, 12.

Sinclair, A. A. H. and Dott, N. M. (1931). I Ibid., 51, 232.

Traquair, H. M. (1942). Intro. to Clin. Perimetry, 4th Edition, p. 232. London.

Wagener, H. P. and Cusick, P. L. (1937). Arch. Ophthal. $18,887$.

Weinberger, L. M. and Webster, J. E. (1941). Ibid., $25,128$.

Wildbrand, H. u. Saenger, A. (1913). Die Neurologie des Auges. Wiesbaden. 